\title{
BAGAIMANA GENERASI FIKIH INDONESIA MENDATANG?
}

\section{Oleb: Muhammad Latif Fauri, MSI., MA**}

\author{
Judul Buku : Muslim Legal Thought in Modern Indonesia \\ Penulis : R. Michael Feener \\ Penerbit : Cambridge University Press \\ Tahun terbit : 2007 \\ Halaman : 290 halaman \\ ISBN-10 : 052187775X
}

Masyarakat maklum bahwa persoalan kemanusiaan dari waktu ke waktu semakin rumit Mengandalkan perangkat epistemologi dan produk pemikiran lama tentu tidak cukup untuk menjawab. Pengembangan ilmu pengetahuan dan teknologi yang mengarah pada lahirnya ide-ide brilian sangat diperlukan. Dalam masalah hukum Islam, menjadi kesepakatan di antara pakar bahwa formulasi fikih yang diproduksi para ulama sejak abad 7 Masehi perlu diperbarui agar kontekstual dan relevan dengan dinamika zaman. Jika membaca karya besar Humphreys yang diterbitkan awal 90 an, Islamic History: $A$ Framework for Inquiry khususnya pada bab 9, kita menjadi semakin yakin bahwa fikih produk ulama' klasik memang tidak cukup memadai sebagai rujukan bagi kehidupan sosial dan ekonomi. Bahkan lebih ekstrim lagi, dengan menganalisis isu perdagangan pada masa awal Islam, dia menyimpulkan bahwa tidak mungkin menggunakan fikih untuk merespon perubahan-perubahan yang terjadi dalam sejarah institusi perekonomian Islam. Ibn Rusyd dalam Bidayat nya juga sudah mencatat bahwa realitas yang selalu berkembang (ghair mutanabiyab) tidak mungkin dihadapi dengan teks yang statis (mutanabiyab). ${ }^{2}$ Reinterpretasi teks dan reaktualisasi ajaran menjadi kebutuhan mutlak.

Sangat disayangkan bahwa kenyataan pergeseran dan dinamika di dalam fikih ini tidak sepenuhnya dipahami oleh sarjana dari luar Asia Tenggara. Keniscayaan metode hukum Islam (ushul fikib), termasuk ijtihad di dalamnya, yang menghendaki agar hukum selalu berdialog dengan perubahan masyarakat tidak dimaknai sebagai kemampuan fikih untuk fleksibel dan adaptif. M. B. Hooker, ketika mengkaji fatwa-

${ }^{1}$ Stephen R. Humphreys, Iskmic Hirtory: A Framevork for Inquiry, (London, New York: I.B. Tauris \& Co. Ltd, 1991). 
fatwa di Indonesia sejak tahun 1920 an, misalnya fatwa tentang hak dan kewajiban wanita, justru menyimpulkan bahwa tidak ada sumber hukum yang secara konsisten dipakai dalam ijtihad serta adanya pertentangan tentang batasan status hukum. Dia mengatakan bahwa pilihan otoritas (sumber maupun pendekatan) yang digunakan dalam sebuah fatwa sangat eklektis. ${ }^{3}$

Pemahaman menyeluruh terhadap sejarah intelektual umat Islam menjadi faktor kunci. Terutama di Indonesia yang merupakan negara berpenduduk Muslim tetbesar di dunia dan telah menjadi rumah bagi perkembangan progesif pemikiran (hukum) Islam. Dengan berkaca pada sejarah, studi pemikiran hukum Islam di Indonesia selayaknya dikembangkan. Dalam konteks inilah, R. Michael Feener menulis buku yang berjudul Muslim Legal Thoughts in Modern Indonesia. Buku ini diterbitkan oleh Cambridge University Press pada tahun 2007. Sebagaimana catatan Feener, tujuan buku ini adalah memperkenalkan kecenderungan pemikiran intelektual Muslim Indonesia mengenai isu hukum dan masyarakat kepada para pembaca, terutama di luar Indonesia. Feener menunjukkan sejumlah kritik tajamnya terhadap beberapa literatur tentang perkembangan pemikiran Islam di Indonesia. Sederhananya, buku ini memotret debat kontemporer dan reformasi Islam yang terjadi di nusantara mulai akhit abad ke-19 sampai sekarang.

\section{Dari 'Tradisi Cetak sampai Ulama' Baru}

Buku in terdiri dari tujuh bagian. Secara mudah, alur buku ini bisa dibaca secara historis. Bab pertama yang berjudul "Technology, training, and cultural transformation" dimulai dengan sebuah kutipan dari J.G.A Pocock, 'When a change in a society's self

${ }^{2}$ Ibn Rushd, Bidăyat al-mujtabid wa Nibâjat al-mugtacid (Cairo: Maktabat al-khanji, 1994), hal 2.

${ }^{3}$ Dia mengatakan bahwa fatâva from the 1920 s to the present show us that no one source is consistent or entirely consistent dan bahwa there is a bighby degre of ambivalence in defining the boundaries of what "may' and 'showld' of vomen. Lihat M.B. Hooker, Indonesian Islam: Social Change through Contemporary Fatâwâ, (Honolulu: University of Hawaii Press, 2003), khususnya bab III tentang Women: Status and Obligation.

${ }^{4} \mathrm{R}$. Michael Feener adalah spesialis sejarah budaya dan intelektual Timur Tengah dan Asia Tenggara. Dilahirkan di Salem, Massachusetts, dia mendapat pendidikan studi Islam dan bahasa Asing di Universitas Boston, Cornell, dan Universitas Chicago, termasuk di Indonesia, Mesir, dan Yaman. Sekarang, dia cukup aktif meneliti dinamika penerapan syariat Islam di NAD secara kelembagaan. Di National University of Singapore (NUS), dia menjabat sebagai arsociate profersor dan menjadi peneliti senior di The Asia Research Institute's 'Religion and Globalization'. Beberapa buku dan artikel yang dihasilkan antara lain Islam in World Cultures. Comparative Perspectives (Oxford, UK: ABC-Clio, 2004), Islamic Law in Contemporary Indonesia: Ideas and Institutions, editor with Mark E. Cammack, (Harvard University Press, 2007), dan "Indonesian Movements for the Creation of a National Madbhab dalam Islamic Lav and Society (9: 1, 2001), hal 83-115. 
awareness has become at all widely disseminated, that society's styles of thinking and acting bave been irreversibly altered" atau ketika kesadaran masyarakat akan perubahan telah tersebar secara luas maka pola pikir dan perilaku mereka juga akan berubah. Feener menjelaskan bahwa perubahan mendasar pada kategori dan struktur otoritas keagamaan tradisional telah menghasilkan perkembangan yang berarti dalam sejarah intelektual dan institusional Muslim di akhir abad 19 dan awal 20 (hlm. 1). Perkembangan tersebut telah memberi dampak yang cukup besar tidak hanya terhadap insitusi sosial dan keagamaan, tetapi juga bentuk dan isi ajaran Islam dan perdebatan hukum di era modern. Karena itu, tidak mengherankan jika gairah untuk melakukan ijtihad pada masa ini tidak bisa terbendung. Sebagai hasilnya, bebetapa ulama' seperti Ahmad Rifa'i, Kalisasak, dan Kiai Saleh Darat, Semarang, memproduksi kitab-kitab yang secara substansial disesuaikan dengan keadaan masyarakat saat itu. Pembahasan ini bisa ditelaah dalam bab kedua yang berjudul "The open gate of jitibad."

Bertambahnya jumlah kitab selama kurun abad 18 dan 19 sesungguhnya didorong oleh revolusi di bidang teknologi. Mesin cetak berfungsi untuk memproduksi teks dalam oplah besar sehingga mampu memperluas jumlah pembaca. Feener, sebagaimana Ian Proudfoot telah mencatat, ${ }^{5}$ bahwa percetakan Muslim pertama di Asia Tenggara pada tahun 1840-an memproduksi kitab dalam jumlah yang massif dan tentu dapat mereproduksi karya-karya ulama' yang masih berbentuk tulisan tangan. Temuan ini memberikan pertanda bahwa teks-teks tentang masalah ke-Islaman merupakan salah satu bagian penting dari rangkaian besar kegiatan percetakan teks-teks Melayu selama paruh kedua dari abad ke-19. Lebih penting lagi, kegiatan penerbitan ini juga memberi kontribusi penting terhadap tersebarnya kitab-kitab di pesantren di penjuru Nusantara. Selain buku cetak untuk konsumsi pembaca, dalam bidang fikih, persebaran teknologi percetakan juga memiliki dampak terhadap bertambahnya ketersediaan kitab-kitab di luar mazhab Shafi'i yang telah menjadi arus utama di Nusantara (hlm. 7-10). ${ }^{6}$

Tiga bab berikutnya, "An Indonesian madhhab", "Shari'a Islam in a Pancasila nation, dan 'New Muslim intellectuals and the 're-actualization' of Islam" secara garis besar menjelaskan bahwa gerakan pemikitan di atas tetap terjaga sepanjang abad 20 ,

${ }^{5}$ Lihat Ian Proudfoot, “A Formative Period in Malay Book Publishing", in JMBRAS 59 (1986), hal 101-132.

'Pembahasan lebih panjang tentang peran'ulama' nusantata di akhir abad 19 dan awal abad 20 dapat dilihat dalam Jajat Burhanudin, Islamic Krowledge, Authority, and Political Power: The Ulama in Colonial Indonesia,. (Leiden: Leiden University, Disertasi Ph.D, 2007). 
terutama setelah kemerdekaan Indonesia. Di awal tahun-tahun setelah kemetdekaan, para pakar, seperti Hasbi ash-Shiddiqy dan Hazairin, meneriakkan gagasan fikih yang disesuaikan dengan karakter masyarakat Indonesia (fikih mazhab Indonesia atau nasional). Pembaruan fikih ini dilakukan dengan menerapkan pendekatan ilmu-ilmu sosial dalam proses ijitihad. Di era 70 -an sampai 90 -an, gerakan ini diteruskan oleh toksoh seperti Nurcholish Madjid dan Munawir Sadzali. Reaktualisasi, kontekstualisasi, bahkan kodifikasi menjadi kata kunci dari usaha mereka semua. Kelompok inilah yang dalam bab keenam "The new 'ulama"'mendapat penyebutan sebagai ulama" baru. Kegiatan ini tetap berlanjut sampai abad 21, khususnya setelah reformasi Indonesia tahun 1998. Tidak cukup kontekstualisasi, gerakan kontemporer ini mengusahakan formulasi hukum Islam yang liberal dan sensitif terhadap isu kesetaraan gender, lintas agama, dan hak-hak sipil.

\section{Generasi hukum Islam Indonesia mendatang?}

Pertanyaan di atas merupakan terjemahan dari bagian diskusi terakhir "Next genartion fiqb?"sebelum kesimpulan. Bagian ini, menurut saya, merupakan kontribusi terpenting dari penelitian Feener ini. Dia merekam produk pemikiran intelektual Muslim di bidang hukum Islam pada era reformasi Terdapat penjelasan tentang tematema beserta lembaga, seperti JIL, P3M dan JIMM, yang turut meramaikan konstelasi pemikiran hukum Islam (hlm. 182-207). Sayangnya, Feener tidak memberi penjelasan mengapa tanda tanya dibubuhkan pada judul bab ini. Kita hanya bisa menerka apa maksud di baliknya. Bisa jadi, Feener memang secara sengaja membiarkannya secara terbuka agar fikih Indonesia, seperti selama ini telah betlangsung, selalu menjadi konsumsi ruang publik. Artinya, sebagai imbas demokrasi, siapapun berhak untuk berpartisipasi dalam panggung wacana ini. Atau, karena konsekuensi pendekatan historisnya, tidak arif jika harus mengakhiri rekaman sejarah intelektual ini dengan memberi kesimpulan bahwa apakah pemikiran fikih Indonesia ke depan akan didominasi oleh kaum liberal atau fundamentalis.

Terlepas dari itu, pembacaan yang komprehensif cum akademis selalu dibutuhkan untuk melihat hukum. Islam Indonesia dulu, sekarang, dan masa depan. Di saat yang lain, para penggiat kajian hukum Islam juga memiliki tanggung jawab moral dalam menentukan masa depan yang sesungguhnya. Umat dengan betbagai persoalan yang dihadapinya membutuhkan jawaban konkrit. Sudah saatnya para intelektual tidak melulu menjadi kaum melangit dan menelurkan gagasan abstrak. 
Kendati tema ini bukan hal yang batu, kelebihan buku ini terletak pada cakupan pembahasan yang komprehensif, meliputi perkembangan pemikiran hukum Islam di Indonesia dari era kolonial sampai era reformasi. Sebagian besar buku yang sudah ada hanya membahas episode tertentu dari rangkaian panjang dinamika hukum Islam Indonesia. Misalnya bagian terbesar dari buku Hukum Islam di Indonesia, ditulis oleh Mahsun Fuad, adalah studi perbandingan pemikitan tokoh penggagas hukum Islam madzhab Indonesia, seperti Hazairin dan Munawir Sadzali ditinjau dari perspektif pembangunan. ${ }^{7}$ Ditulis dalam bahasa Inggris, buku ini sangat bermanfaat bagi para penggiat (terutama dari Barat) kajian hukum Islam dan sosial, studi Asia Tenggara dan perbandingan hukum dan undang-undang. Selain itu, Feener terlihat sangat serius dalam menulis buku ini. Terbukti, tetdapat banyak data-data baru yang tidak semua penulis, terutama dati Indonesia, dapat memperolehnya. Kekayaan sumber ini juga menambah nilai positif buku.

* Lulusan MA Islamic Studies Universitas Leiden, Belanda dan dapat dibubungi di m_latiffauzi@yaboo.com.

${ }^{7}$ Lihat Mahsun Fuad, Hukum Islam di Indonesia, (Yogyakarta: LKiS, 2005). 